NOTAS

\title{
DESCARTES: CIENCIA DEL ESPÍRITU Y CIENCIA DE LA NATURALEZA \\ Milagros Mier*
}

$\mathrm{E}_{\mathrm{l} \text { filósofo Carl von Weizsäcker }}$ hará unos cuarenta años describía en su Discurso sobre Descartes y la ciencia de la naturaleza en la Edad Moderna la situación de nuestro tiempo, caracterizado por la disociación de la conciencia.

Si consideramos el estado actual no sólo de la filosofía, sino también de toda la Universidad, no solamente de la ciencia, sino de toda la conciencia oficial, vemos que está dominada por la separación y extrañeza entre espíritu y materia. Ciencia del espíritu y ciencia de la naturaleza apenas si tienen un lenguaje común en el que poder dialogar y con frecuencia incluso se enorgullecen de esa extrañeza. Quien considera al hombre como hombre, como ser con alma, como espiritual, como responsable, sabe

* Departamento Académico de Estudios Generales, ITAM. con frecuencia demasiado poco de su cuerpo y de la tierra sobre la que está, o de la manera como nuestras máquinas mueven hoy la materia. Quien por el contrario es capaz de mover la materia con máquinas, sabe con frecuencia demasiado poco del hombre y de su responsabilidad para con él. ${ }^{1}$

Miremos hacia atrás en la historia. Miremos al filósofo que, no sin razón, es considerado como el padre de la filosofía de la Edad Moderna, el francés René Descartes, nacido hace cuatrocientos años. Con él, el primer gran racionalista, comienza una nueva metafísica, que parece estar libre de todas las ataduras tradicionales. Él llega, por la duda radical acerca de la realidad, a dos ámbitos de ser existentes uno al lado del otro: el de pensar, es decir, el de la existencia es-

${ }^{1}$ Eckart Heimendahl, Fisica y Filosofia, 1969, Madrid, Guadarrama, p. 157. 
NOTAS

piritual, y el de la extensión, o materia. Esta disociación se expresa actualmente como una oposición de conceptos: objetividad y subjetividad. La objetividad expresa la exigencia de un objeto, de algo imparcialmente conocido y concebido por sí mismo. El concepto se refiere a la adecuación -objetiva-conforme a la cosa, que por tanto no está influenciada o no depende de opiniones, intereses o valoraciones: de condiciones subjetivas.

Rendir un homenaje a un autor significa para mí revaluarlo, esto es, entablar un diálogo con sus escritos que merecen ser rescatados de aquéllos que en nombre de la eficacia y no de especulaciones vacías e inútiles afirman que lo digno de apreciarse en Descartes es su ruptura con la tradición filosófica que tenía como temas fundamentales: la vida, Dios, la libertad. Por fin, -gritan- ha triunfado la certeza sobre la sabịduría.

Y es que, la oposición de lo objetivo y subjetivo ha sido exagerada hasta tal punto, que del lado subjetivo ya no se habla de verdad. Pero mientras esto permanezca así, ni el pensamiento científico puede ser corregido por medio de un pensamiento orientado al hombre, ni el humanismo tradicional puede tampoco ser corregido por medio de la objetividad científica, porque carecen de un lenguaje común.

Descartes no separa la filosofía de la ciencia. En su proyecto filosófico se hallan estrechamente vinculados y son sólidamente interfuncionales método, física y metafísica. En efecto, Descartes está convencido-como lo manifiesta en sus Principios de Filosofía-, de que el saber en conjunto, esto es, "toda la filosofía, es como un árbol, cuyas raíces son la metafísica, el tronco es la física, y las ramas, que proceden del tronco son todas las demás ciencias". ${ }^{2} \mathrm{~W}$. Whewell refiriéndose a Descartes señala que los descubridores físicos se han diferenciado de los especuladores estériles no porque en sus cabezas no tuviesen ninguna metafísica, sino por el hecho de que tenían una metafísica correcta, mientras que sus adversarios tenían una equivocada; y además, porque mezclaron su metafísica con su física, en vez de mantenerlas separadas.

Así para Descartes, la metafísica, nos dice de qué y cómo está hecho el mundo. Por consiguiente, la ciencia -asevera el filósofo en las Reglas para la dirección del espiritu- se ocupará "sólo de aquellos objetos sobre los cuales nuestro espíritu parece capaz de adquirir conocimientos ciertos e indudables". ${ }^{3}$ Quiso entonces llegar

${ }^{2}$ René Descartes, Principios de Filosofia, 1974, México, Porrúa, p. 94.

${ }^{3}$ René Descartes, Reglas para la dirección del espíritu, 1974, México, Porrúa, p. 96. 


\section{NOTAS}

a las raíces, a los cimientos, para que después fuera posible recoger frutos maduros, y al mismo tiempo descalificar a aquellos que pregonan el triunfo de la certeza sobre la sabiduría; al contrario, él hizo suya aquella distinción de que hablaba Agustín de Hipona en De Trinitate: "La ciencia - decía Agustín - tiene por objeto el conocimiento racional de las cosas temporales y mudables del mundo sensible. La sabiduría se ocupa del conocimiento intelectual de las realidades y verdades eternas e inmutables del mundo suprasensible e inteligible." ${ }^{4}$

Descartes halló la justificación de la separación racionalista de un mundo corporal y espiritual en la prueba de la existencia de Dios. Empieza reduciendo toda certeza al pensar y nos dice: "El pensamiento existe. Solamente él no puede ser separado de mí. Soy, existo. Esto es cierto."5 En la Meditación sexta (sobre la existencia de las cosas materiales) lleva este pensamiento hasta la separación de lo corporal:

Y aunque quizá -dice- tengo un cuerpo que está íntimamente unido conmigo, no obstante, como por una parte tengo una idea cla-

${ }^{4}$ San Agustín, Los libros sobre la Trinidad, 1969, Madrid, BAC, p. 217.

${ }^{5}$ René Descartes, Discurso del método, 1979, México, Porrúa, p. 22. ra y explícita de mí mismo, en cuanto soy una cosa solamente pensante, no extensa, y como por otra parte tengo también una clara idea del cuerpo, en cuanto que es una cosa extensa, no pensante, es cierto que yo soy verdaderamente distinto de mi cuerpo y puedo existir sin él. ${ }^{6}$

Después de recordarnos la diferencia, con respecto a la certeza, de la existencia del sujeto y de la existencia de los objetos; subraya que la primera no puede ponerse en duda, excepto a través de la hipótesis de un creador engañador. Así, debe inquirir "tan pronto como sea posible" si hay un Dios y, si lo hay, si podría ser engañador.

Pero, ¿Cómo llega el yo hasta la existencia de Dios?

- Primero, causalmente. Para Descartes es indudable que el hombre encuentra dentro de sí mismo la idea de un ser perfecto, infinito. ¿De dónde proviene esta idea? No de nosotros que somos imperfectos y finitos, sino de Dios mismo que la ha sembrado en nosotros. La idea de Dios es una idea innata o ingénita al hombre.

${ }^{6}$ René Descartes, Meditaciones metafisicas, 1974, México, Porrúa, p. 84. 
NOTAS

- Segundo, ontológicamente, deduciendo de la idea la existencia. Descartes recurre al famoso argumento de Anselmo de Canterbury, al que desde Kant se le conoce con el apelativo de ontológico, pero ahora naturalmente desde el supuesto de su principio del conocimiento claro y distinto. Todo cuanto nosotros reconocemos clara y distintamente pertenecer a la verdadera naturaleza de una cosa debe pertenecerle en efecto. Mas la idea de Dios no debe confundirse con una idea cualquiera. Clara y distintamente reconocemos que Dios es el ser perfectísimo y que a sus perfecciones pertenece también su existencia; el ser sumamente perfecto no puede no tener la máxima perfección. Por tanto, con la idea de Dios como ser perfectísimo viene ya dado el hecho de que en efecto existe.

Pero en este conocimiento, ¿cómo podemos estar seguros de no equivocarnos o de no ser engañados por un espíritu falaz? He aquí la respuesta de Descartes: Si Dios fuese un espíritu engañador, no podría ser el más perfecto. Pues engaño y embuste son signos de debilidad e imperfección. El mismo concepto o idea del ser sumamente perfecto, por tanto, no sólo implica la existencia, sino también la veracidad y bondad de Dios. Un Dios mentiroso es imposible. Partiendo de aquí ya no es difícil pasar a las cosas materiales del mundo exterior. Siendo Dios veraz y bueno, el hombre puede estar seguro de sí mismo y de las cosas materiales que le rodean. Sin embargo, si bien es cierto que Dios es veraz y no engaña, también es cierto que el hombre yerra. ¿Cuál es entonces el origen del error? Ciertamente el error no es imputable a Dios sino al hombre, porque no siempre se muestra fiel a la claridad y la distinción. En la Cuarta meditación Descartes da solución a este problema atribuyendo el error a la inadecuada presión de la voluntad sobre el intelecto. "Si me abstengo de emitir un juicio sobre una cosa, cuando no la concibo con la suficiente claridad y distinción, es evidente que hago un uso óptimo del juicio y no me engaño; pero si decido negar o afirmar esa cosa, entonces ya no empleo como es debido mi libre arbitrio; y si afirmo lo que no es cierto, es evidente que me engaño; porque la luz natural nos enseña que el conocimiento del intelecto debe preceder siempre a la determinación de la voluntad. Y precisamente en este mal uso del libre arbitrio se encuentra la privación que constituye la forma del error."7

${ }^{7} \mathrm{Ibid}$, p. 76. 
Con esta inmensa confianza en el hombre y en sus facultades cognoscitivas y después de haber señalado las causas y las implicaciones del error, Descartes puede avanzar ahora hacia el conocimiento del mundo y de sí mismo, en cuanto se halla en el mundo. Ya se ha justificado el método, se ha fundamentado la claridad y la distinción, y la unidad del saber ha sido reconducida a su fuente, la razón humana, sostenida e iluminada por la garantía de la suprema veracidad de su Creador.

Es así que para Descartes, la percepción del poder de Dios es incluso más clara y distinta que las percepciones de necesidad matemática; con lo que tenemos derecho a sostener que las últimas percepciones están subordinadas al poder de Dios. De manera similar, la percepción de la perfección de Dios es más clara y distinta que nuestras mejores intuiciones de verdad matemática y científica. Tenemos derecho a confiar en las últimas sólo porque reciben "confirmación" de la percepción más evidente de todas. Gracias a la veracidad de Dios, mi certeza subjetiva se transforma en certeza objetiva.

Si pretendiéramos juzgar aquí el pensamiento de Descartes, convendría recurrir a Kant quien demuestra la "imposibilidad de una prueba ontológica de la existencia de Dios", cayéndose así la piedra angular del edificio cartesiano. Sin embargo, la intención no es refutar al filósofo, tarea que por lo demás ya hicieron otros mejor de lo que yo podría hacerlo, sino mostrar cómo Descartes aún respetando los ideales científico matemáticos de claridad y distinción, de exactitud, eficiencia y objetividad, tuvo el mérito de restaurar audazmente el sentido metafísico y sus ideas fundamentales: Dios, el espíritu del hombre, la libertad. Objetividad, neutralidad e imparcialidad en la ciencia carecen de sentido cuando no se tiene en todo momento conciencia del sistema total de relaciones y de los intereses rectores del saber, cuando no se tienen presentes los supuestos metodológicos, las consecuencias prácticas y la responsabilidad personal y social. Los métodos y la ciencia no deben ser fines en sí mismos, sino simples medios para la humanización del hombre. Porque la ciencia natural sólo tiene sentido como base de la imagen moderna del mundo y de la moderna civilización y cultura cuando no se hace de la base el edificio entero -como lo vio Descartes-; cuando junto a los métodos científico-naturales se admiten también los de otras ciencias, esto es, los de las ciencias del espíritu. Toda ciencia que se absolutiza debe ponerse en entredicho. 